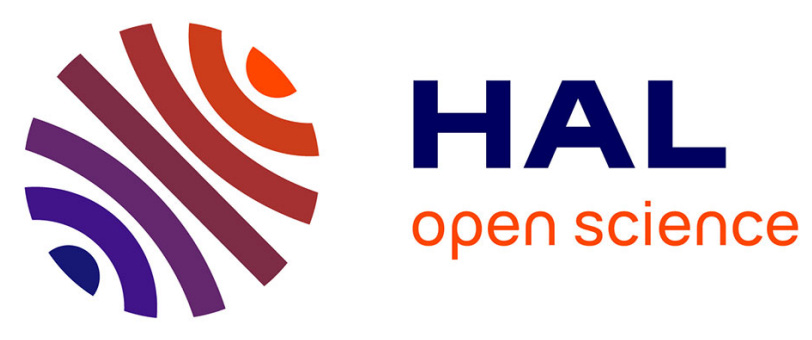

\title{
High nonlinear urban ground motion in Manila(Philippines) from 1993 to 2010 observed by DInSAR: implications for sea-level measurement
}

Daniel Raucoules, Gonéri Le Cozannet, Guy Wöppelmann, Marcello de Michele, Médéric Gravelle, Arturo Daag, Marta Marcos

\section{To cite this version:}

Daniel Raucoules, Gonéri Le Cozannet, Guy Wöppelmann, Marcello de Michele, Médéric Gravelle, et al.. High nonlinear urban ground motion in Manila(Philippines) from 1993 to 2010 observed by DInSAR: implications for sea-level measurement. Remote Sensing of Environment, 2013, 139, pp.386397. 10.1016/j.rse.2013.08.021 . hal-00863850

\section{HAL Id: hal-00863850 https://hal.science/hal-00863850}

Submitted on 20 Sep 2013

HAL is a multi-disciplinary open access archive for the deposit and dissemination of scientific research documents, whether they are published or not. The documents may come from teaching and research institutions in France or abroad, or from public or private research centers.
L'archive ouverte pluridisciplinaire HAL, est destinée au dépôt et à la diffusion de documents scientifiques de niveau recherche, publiés ou non, émanant des établissements d'enseignement et de recherche français ou étrangers, des laboratoires publics ou privés. 


\section{observed by DInSAR: implications for sea-level measurement}

High nonlinear urban ground motion in Manila (Philippines) from 1993 to 2010

Raucoules, Daniel ${ }^{a^{*}}$; Le Cozannet, Gonéria; Wöppelmann, Guy ${ }^{b}$; de Michele, Marcello ${ }^{a}$; Gravelle, Médéric $^{\text {b; Daag, } \text { Arturo }^{c} ; \text { Marcos, Marta }}{ }^{\text {b }}$

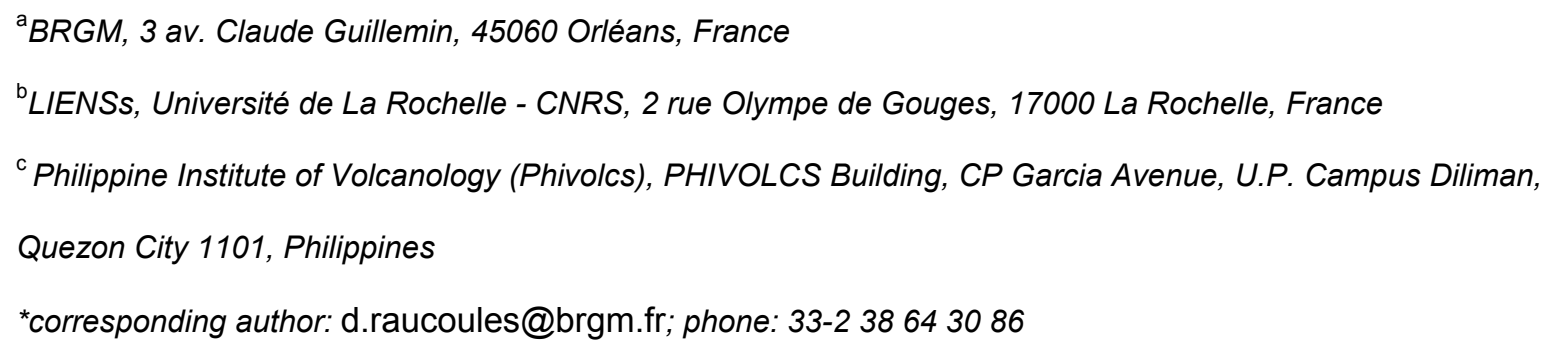

Keywords: DInSAR; subsidence; sea level rise estimation; Manila

Highlights:

- Differential SAR interferometry has been applied in Manila (Philippines)

- High nonlinear ground motion was observed during 1993-1998 and 2003-2010.

- A comparison with independent ground-level measurements (GPS, DORIS, and Tide Gauge) was carried out.

- The consequences for sea-level estimation were analyzed using a local tide gauge and GPS station.

\section{ABSTRACT:}

In coastal low-lying urban areas, vertical ground motions can significantly exacerbate the hazards related to sea-level rise. However, their spatial extent, their temporal evolution, and even sometimes their existence are often poorly known. This study aims to monitor variable urban ground motion (uplift and subsidence) from 1993 to 2010 in the metropolitan area of Manila, Philippines. Because high subsidence rates have been reported in this city in previous studies, conventional differential SAR interferometry (DInSAR) was applied with an adapted stacking procedure to the archive of ERS and Envisat satellite images to produce surface deformation-velocity maps for different periods. The results showed that the city is locally affected 
by vertical ground motions on the order of $15 \mathrm{~cm} / \mathrm{yr}$. Moreover, the spatio-temporal evolution of the groundmotion phenomena is highly nonlinear. These results are in good agreement with previous studies focused on groundwater use in Manila and in the Marikina Fault Valley, suggesting a plausible interpretation of the processes causing surface motion. Incidentally, the ground motions are affecting the locations of several geodetic instruments, including a tide gauge with sea-level records starting in 1902, two permanent GPS (Global Positioning System) stations, and a DORIS (Doppler Orbitography and Radiopositioning Integrated by Satellite) station. A major implication of those large and locally variable ground motions is that they impede the use of the nearby GPS and DORIS data to correct the tide-gauge records and to derive robust sea-level trends associated with climate change.

(1)

\section{Introduction}

As sea level rises, there is increased concern about the growing urbanization of the world's coastal zones and the related coastal hazards, particularly in Southeast Asia (McGranahan et al., 2007; Nicholls \& Cazenave, 2010). However, climate-induced sea-level rise is not the only process leading to changes in mean relative sea levels in coastal cities: the local relative sea-level rise (i.e., as experienced on the coast) can be significantly affected by vertical ground motions, subsidence or uplift, either due to natural processes (e.g., global isostatic adjustment, tectonics, sediment compaction) or to human activities (e.g., groundwater pumping, hydrocarbon extraction).

In a recent assessment of the exposure of the world's coastal cities to coastal submersion hazard, Hanson et al. (2011) have highlighted that subsidence or uplift (1) affects many important coastal cities worldwide and (2) can be in the same order of magnitude or greater than climate-induced sea-level rise. It is therefore important to take into account these processes for evaluating how changes in sea level may affect coastal cities in the future. However, while coastal ground motions are recognized important, they are in practice often poorly known. In many cases, little information is available about the processes that generate ground motion (e.g., location and rates of groundwater pumping) and on ground-motion patterns. In addition, vertical ground motions often reveal strong spatial and temporal variability, so that their mapping is a complex task. 
As a complement to in-situ monitoring (e.g., using GPS or leveling), space-borne Differential Synthetic Aperture Radar Interferometry (DInSAR) provides a means to deliver a comprehensive mapping of surface deformation (e.g., Brooks et al., 2007; Lagios et al., 2006; Raucoules et al., 2008; Bock et al., 2012; Chaussard et al., 2013). The principle of DInSAR is to infer ground-motion displacements from the evolution of the phase of space-borne Synthetic Aperture Radar between two or more satellite passes. Although the technique encounters limitations in vegetated areas, it can be applied efficiently in urban environments. In addition, provided that the displacements are not too rapid given the geometric and temporal characteristics of the available SAR scenes time series, the method has been shown to be efficient for monitoring slightly nonlinear ground motions (e.g., Kim et al., 2010).

Using SAR data acquired by the ERS and Envisat satellites from 1993 to 2010, this study uses DInSAR to monitor ground motions affecting Manila, on Luzon Island in the Philippines. Located on a coastal floodplain between the eastern part of Manila Bay and Laguna de Bay, the Manila metropolitan area is considered to be highly vulnerable to the adverse effects of flooding and of sea-level rise (World Bank, 2010). The 2010 population census reported that Manila has a population of 11.8 million inhabitants (National Statistics Office, Republic of the Philippines, 2010). In addition, previous studies have reported that the city is subject to ground motions: as the population has grown, water demand and groundwater extraction have drastically increased (Clemente et al., 2001), causing ground surface motions in the city of Manila, as well as in other locations around Manila Bay (Siringan \& Ringor, 1998; Rodolfo \& Siringan, 2006; Daag et al., 2011, Clemente et al., 2001). Finally, the eastern part of the city is crossed by a seismic fault, the Marikina Fault Valley (Rimando \& Knuepfer, 2001).

Interestingly, the city hosts several important geodetic instruments which are potentially useful for estimating contemporary sea-level rise. Tide-gauge measurements have been recorded in Manila since 1902, which makes this the longest time series in Southeast Asia. Therefore, this gauge belongs to the "Global Core Network" of the Global Sea Level Observing System (GLOSS). However, the tide gauge is suspected of being affected by ground motions, presumably due to groundwater withdrawal, at least since the 1950s (Santamaría Gómez et al., 2012). To correct sea-level time series from these ground motions (as proposed by Wöppelmann et al., 2007), several geodetic instruments located in metropolitan Manila might be used: two GPS stations and a DORIS (Doppler Orbitography and Radiopositioning Integrated by 
Satellite) station (Willis et al., 2010). However, these instruments are located several kilometers away from the tide gauge (Fig. 1). Because no repeated leveling surveys are presently available in the GLOSS data repositories (www.sonel.org; www.psmsl.org), it is unknown whether the location of these instruments has been affected by the ground-motion processes.

In this study, DInSAR is applied to the Manila urban area with the objective of providing preliminary answers to the following questions:

(1) What was the spatial and temporal variability of ground-surface deformations in Manila from 1993 to $2010 ?$

(2) To which extent do these deformations affect the locations of the tide gauge and of the GPS and DORIS stations?

(3) What are the possibilities for using sea-level time series before 1993 in Manila?

The paper proceeds as follows: Part 2 describes the data and the DInSAR processing. Part 3 reports on the observations of surface deformations and provides preliminary interpretations in relation to previous studies focused on groundwater extraction and on the Marikina Valley Fault. Finally, in Part 4, the paper discusses to which extent the combination of permanent GPS measurements and DInSAR is able to provide correction for long-term tide-gauge time series for this particular site, considering the high observed deformation rates and their irregular temporal evolution.

\section{Processing procedures and data}

\subsection{Choice of an adapted DInSAR processing procedure}

Several DInSAR algorithms can be used for processing SAR data, from conventional DInSAR (e.g., Massonnet and Feigl, 1998), possibly with an adapted stacking procedure (e.g., Usai et al., 2003) to advanced techniques such as Persistent Scatterers Interferometry (PSI, e.g., Ferretti et al., 2000; Wegmuller et al., 2004) or Small Baseline Subsets (SBAS, e.g., Pepe et al., 2005). The quality of the 
123 results obtained by each method can vary widely depending on the area of interest and on the available

124 SAR images. In places such as the densely urbanized Manila metropolitan area, conventional DInSAR

125 often provides interferograms with good coherence even over large time spans (a few years), provided that

126 the perpendicular baselines are not too high. However, these interferograms are affected by atmospheric

127 effects, typically leading at the spatial wavelength of this study ( 20 km) to errors of the order of one

128 centimeter, but in certain cases to errors larger than a fringe (e.g., Hanssen, 2001). When a sufficient

129 number of SAR scenes have been acquired, stacking procedures can average and reduce atmospheric

130 effects, which are supposed to be spatially correlated and temporally uncorrelated. With this assumption,

131 uncertainty due to atmosphere is reduced as the inverse of $\sqrt{ } N$, where $N$ is the number of independent

132 interferograms (Zebker et al.,1997; Peltzer et al., 2001). For the presented results, that corresponds to

133 approximately $4 \mathrm{~mm} / \mathrm{yr}$ for the ERS data set (with only thirteen images) and better than $1 \mathrm{~mm} / \mathrm{yr}$ for the

134 EnviSat/ASAR data set.

135 Stacking procedures are relatively easy to use and can often provide information about potentially

136 nonlinear ground motions in the order of a few centimeters per year (e.g., Le Mouelic et al., 2005). Finally,

137 advanced techniques such as PSI can be efficient if PS density is sufficient and can reach high precision.

138 However, in the case of spatially and temporally variable rapid ground deformations, PSI techniques (in the

139 standard procedure based on the use of linear or slightly nonlinear displacement evolution models) can be

140 affected by spatial and temporal unwrapping errors that result in underestimation of the velocity and

141 incorrect atmospheric phase screen estimation (Raucoules et al., 2009). When no prior information on

142 patterns of urban ground deformations is available, stacking procedures are easily applicable and can

143 provide maps of vertical ground motions. This approach was selected for the case study in Manila.

144 Combinations of ascending and descending modes can in certain cases (e.g., Wright et al., 2004) be used

145 for separating vertical motions other than horizontal (in fact, mostly East-West because of the orbital

146 orientation). However, in the study area, the data archive in ascending mode is insufficient (in fact only one

147 ASAR pair is archived) to derive deformation maps for the period of interest. Assumptions on the direction

148 of motion are therefore needed for interpretation.

149

$150 \quad 2.2$ Description of data and processing

151 
Using a series of ERS 1-2 images between 1993 and 2000 (Table 1) and ASAR/EnviSAT data between

1532003 and 2010 (Table 2), differential interferograms having perpendicular baselines shorter than $300 \mathrm{~m}$

154 were processed. Then, as suggested, e.g., by Le Mouelic et al., (2005), a subset of trustworthy

155 interferograms was selected visually by rejecting noisy phases and data obviously affected by atmospheric

156 effects. In addition to rejecting low-coherence interferograms, the interferograms were compared by pairs

157 to identify obvious atmospheric effects. Figures $2 a$ and $2 b$ show the selected interferograms and related

158 acquisition times and perpendicular baselines. Deformation is assumed (even for nonlinear deformation) to

159 have a certain temporal correlation, whereas atmosphere turbulence is assumed uncorrelated. By

160 identifying similarities and dissimilarities on the interferograms, it was possible to detect acquisitions

161 affected by strong atmospheric effects that could severely impair a stacking result. Finally, interferograms

162 were stacked for the entire observation periods [1993-1998 (ERS) and 2003-2010 (Envisat)] and for sub-

163 periods of three years. We focused on time spans shorter than 400 days to avoid unwrapping errors in

164 interferograms with more than five or six fringes and to limit temporal decorrelation. Note that the ERS

165 acquisition for 2000 does not allow production of interferograms meeting the requirements in terms of time

166 span.

167 This processing was carried out using the GAMMA interferometric software (Wegmuller at al., 1998).

2.3 Specific procedures for analyzing temporally variable ground motions and fault-related

170 deformations

171

172 In addition, a principal components analysis (PCA) was performed on the deformation maps to discriminate

173 the areas affected by constant deformation (first component) from those affected by time-varying

174 deformation. Finally, a directional filter was computed for the 2003-2010 deformation maps of the Marikina

175 Valley Fault area (east of Manila) to locate sections of the fault affected by surface motion.

176

177 Table 1: ERS 1-2 acquisitions (track 418)

\begin{tabular}{ll}
\hline Year & Acquisition dates \\
\hline 1993 & 25 July, 29 Aug, 3 Oct \\
1995 & 4 April, 13 June, 31 Oct, 5 Dec \\
1996 & 9 Jan, 19 March, 11 Sept
\end{tabular}


1997

1 Oct, 5 Nov

1998

14 Jan

2000

$23 \mathrm{Feb}$

178 Mean incidence angle: approximately $23^{\circ}$

179

180 
182 Table 2: EnviSat/ASAR acquisitions (track 418)

\begin{tabular}{ll}
\hline Year & Acquisition dates \\
\hline 2003 & 8 Jan, 12 Feb, 19 March, 2 July, 10 Sept, 24 Dec \\
2004 & 28 Jan, 3 March, 12 May, 21 July, 25 Aug, 29 Sept, 3 Nov, 8 Dec \\
2005 & 12 Jan, 16 Feb, 23 March, 27 April, 1 June, 6 July, 10 Aug, 14 Sept, 28 Dec \\
2006 & 1 Feb, 8 March, 12 April, 17 May, 26 July, 17 Jan, 26 July \\
2007 & 17 Jan, 24 Oct, 28 Nov \\
2008 & 12 March, 25 June, 3 Sept, 12 Nov \\
2009 & 21 Jan, 2 Dec \\
2010 & 4 Aug
\end{tabular}




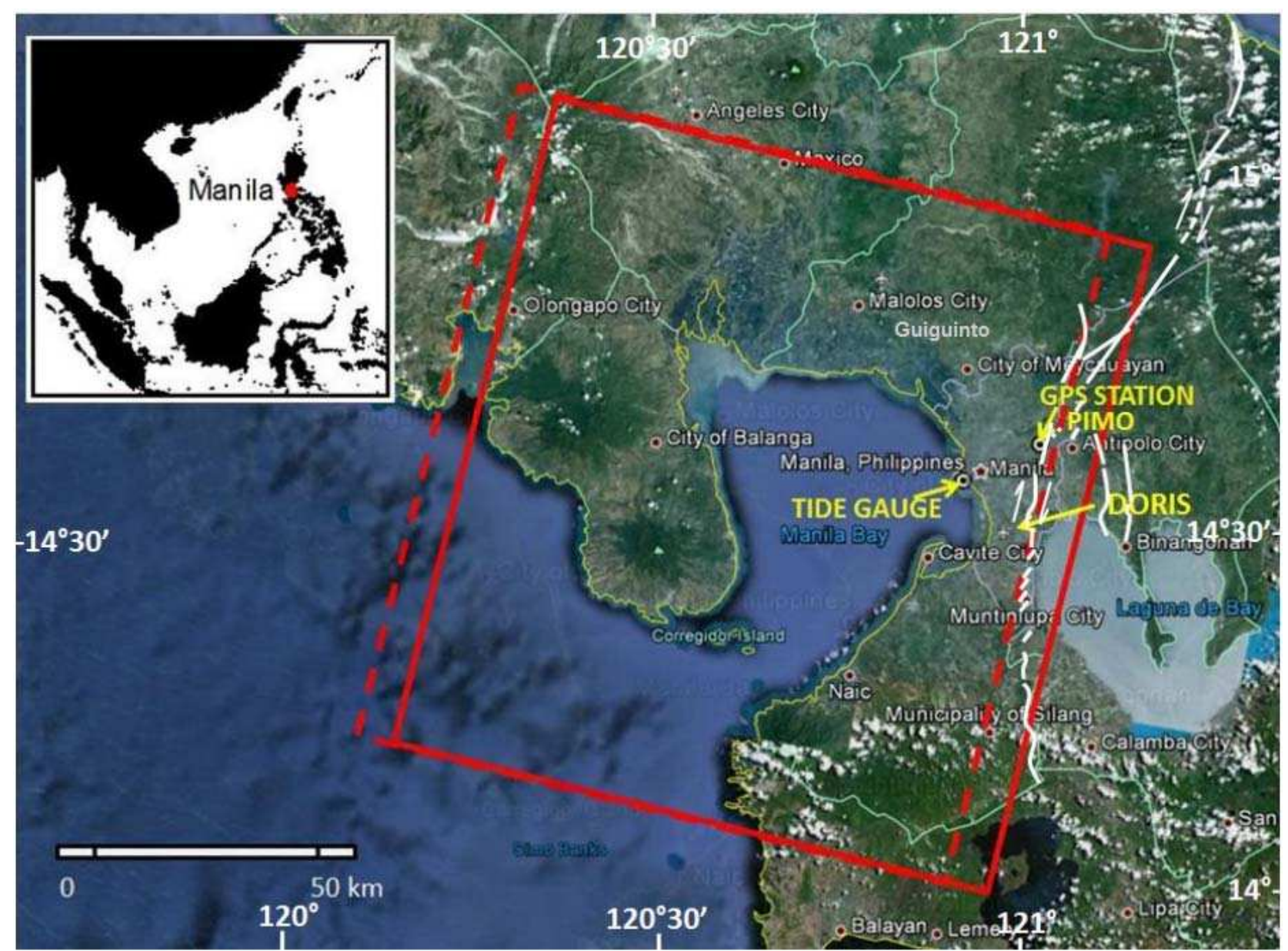

Figure 1: Location of the Manila metropolitan area. This map shows (1) the area covered by the SAR data

187 acquisition frames on Manila Bay, with solid lines corresponding to the ASAR/ENVISAT acquisitions and

188 dashed lines to ERS 1 and 2 data; (2) the position of the Marikina Valley Fault System (MVFS), based on

189 Rimando \& Knuepfer, (2006); the ASAR data cover part the Marikina Valley Fault, whereas the ERS data

190 do not due to a slight westward shift of ERS; (3) the location of the tide gauge, GPS (PIMO), and DORIS

191 stations; the MANL GPS station is located close to the tide gauge (see Fig. 3a), but no reliable vertical

192 velocity could be computed for the study period using the SONEL data repository (www.sonel.org). 


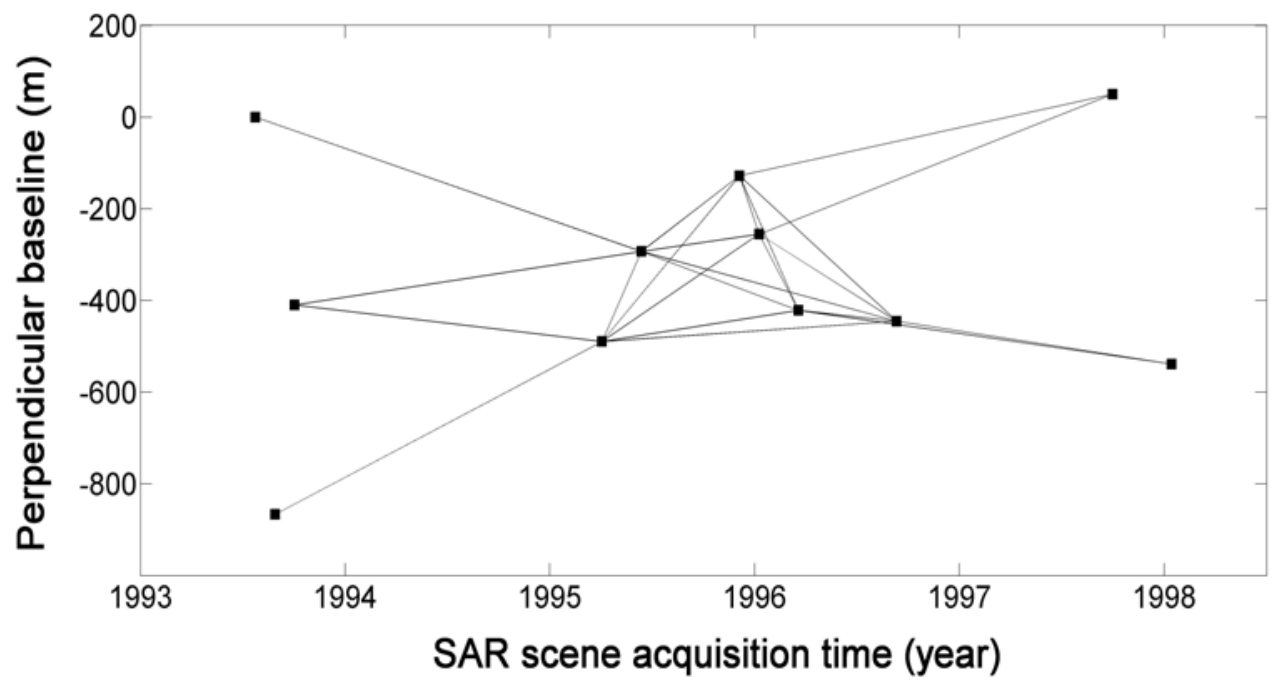

195 Figure 2a: Baseline/time diagram for the ERS 1/2 data. The interferograms used for the study (those that 196 met the requirements in terms of baseline and time span) are represented by vectors with coordinates 197 corresponding to their baselines and time spans. The zero perpendicular baseline refers to the scene 198 acquired on July 25, 1993.

199

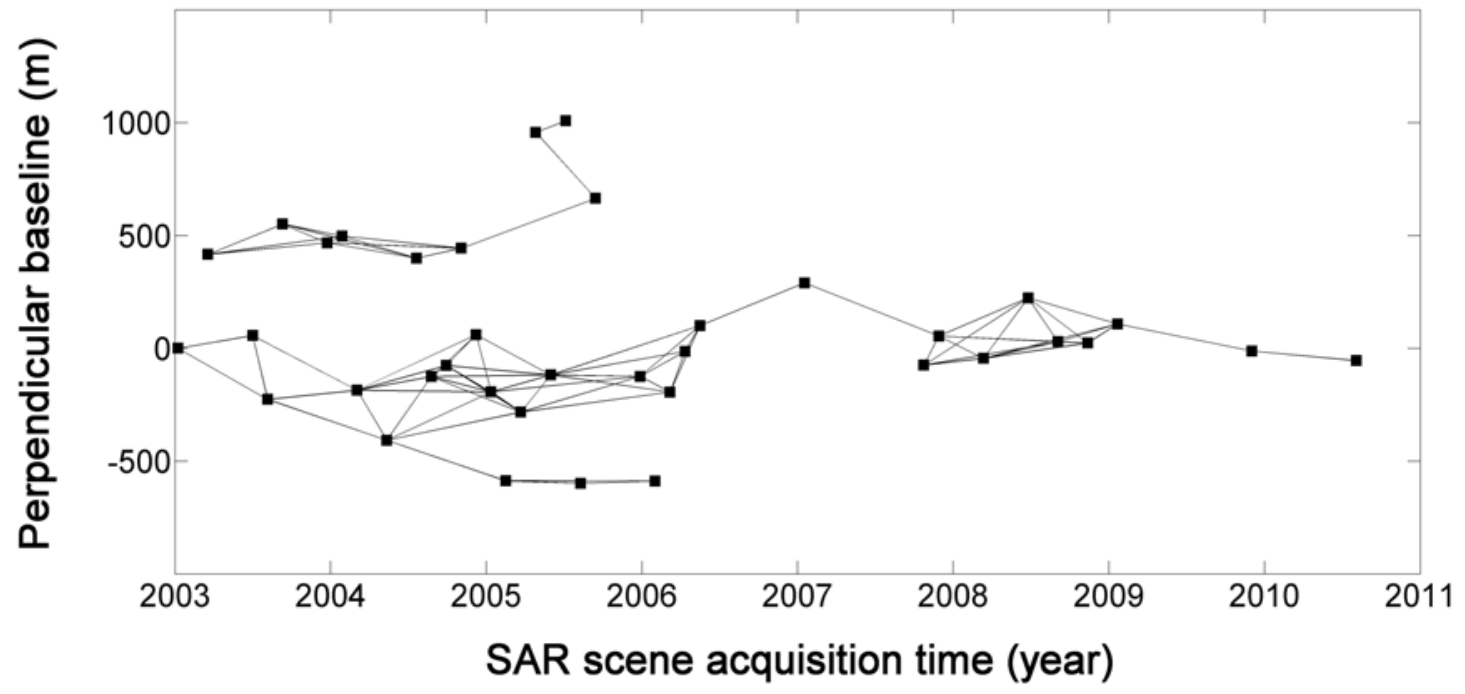

201 Figure 2b: Same as Figure 2a for the EnviSAT/ASAR data. The zero perpendicular baseline refers to the 202 scene acquired on January 8, 2003.

3. Results: observations and preliminary interpretations 
208 Deformation maps were produced as shown in Figs. 3 and 4. The scale corresponds to Line of Sight (LOS) 209 in $\mathrm{cm} / \mathrm{yr}$. Because of the $23^{\circ}$ view angle of the acquisition geometry, the LOS measurement is 2.3 more 210 sensitive to the vertical component of the displacement than to the horizontal. The horizontal component of 211 the subsidence displacement is generally much smaller than the vertical, but in certain cases could be non212 negligible with respect to the vertical, although smaller (e.g., for coal-mining subsidence, the ratio between 213 the maximum horizontal and the maximum vertical components is approximately 0.4; Tandanand \& Powell, 214 1991). On the basis of these two observations, it can be assumed that for subsidence, the measured LOS 215 component is related mostly to the vertical component of the displacement. Under this assumption, 10 $216 \mathrm{rad} / \mathrm{yr}$ would correspond to approximately $4.9 \mathrm{~cm} / \mathrm{yr}$ of vertical motion. However, horizontal displacements 217 probably occur in the Marikina Valley Fault because it is mainly a strike-slip fault. In fact, if the observed 218 motion were mainly due to fault activity and not related to pumping-induced subsidence, the measured LOS 219 displacement would be the projection of an along-fault motion (except on sections of the fault having a 220 more complex motion).

221 Pixels with an interferometric coherence less than 0.3 were considered unreliable and were used to define 222 a mask. Morphological operations (opening and closing) were applied to the mask to remove irregularities 223 before the mask was applied to the interferograms.

224 Because of the generalized surface motion in the area, it is difficult to find a reliable and stable reference 225 point. However, the DORIS instrument provides a local estimate of vertical velocity. The deformation maps 226 were corrected by a value (constant for a given map) to be compatible with the displacement observed by 227 DORIS for the corresponding period (and therefore to convert relative measurements from DInSAR in 228 absolute motion estimates). Values of the DORIS motion rates and a description of the data are given in Section 4.1. 


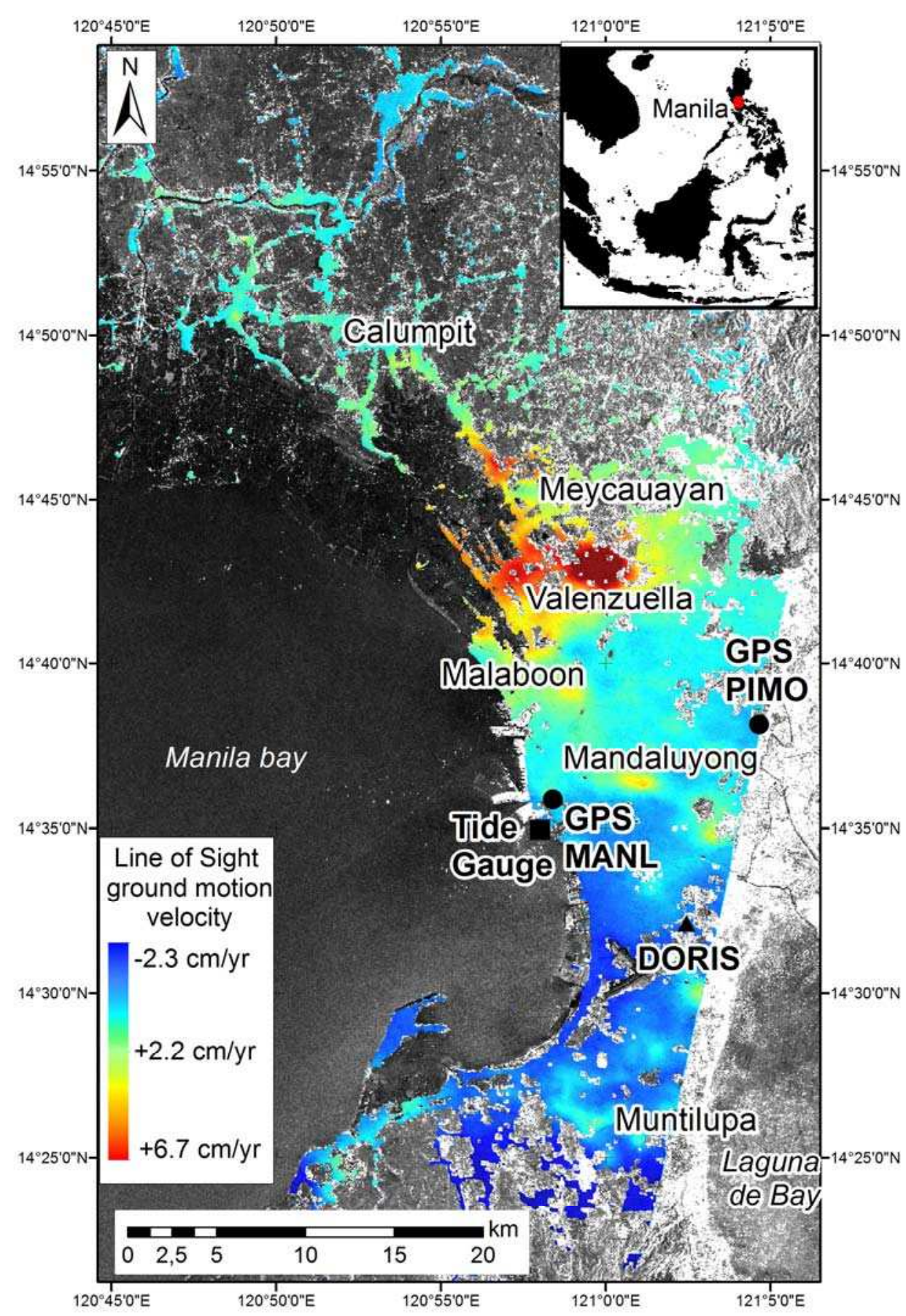

232 Figure 3a: Line of Sight ground motion velocity in cm/yr for the whole 1993-1998 period (ERS 1-2 data).

233 Negative values correspond to displacements towards the sensor (i.e., uplift). For figure readability, the 234 color palette in this figure and in the following velocity maps is saturated at its extreme values. 


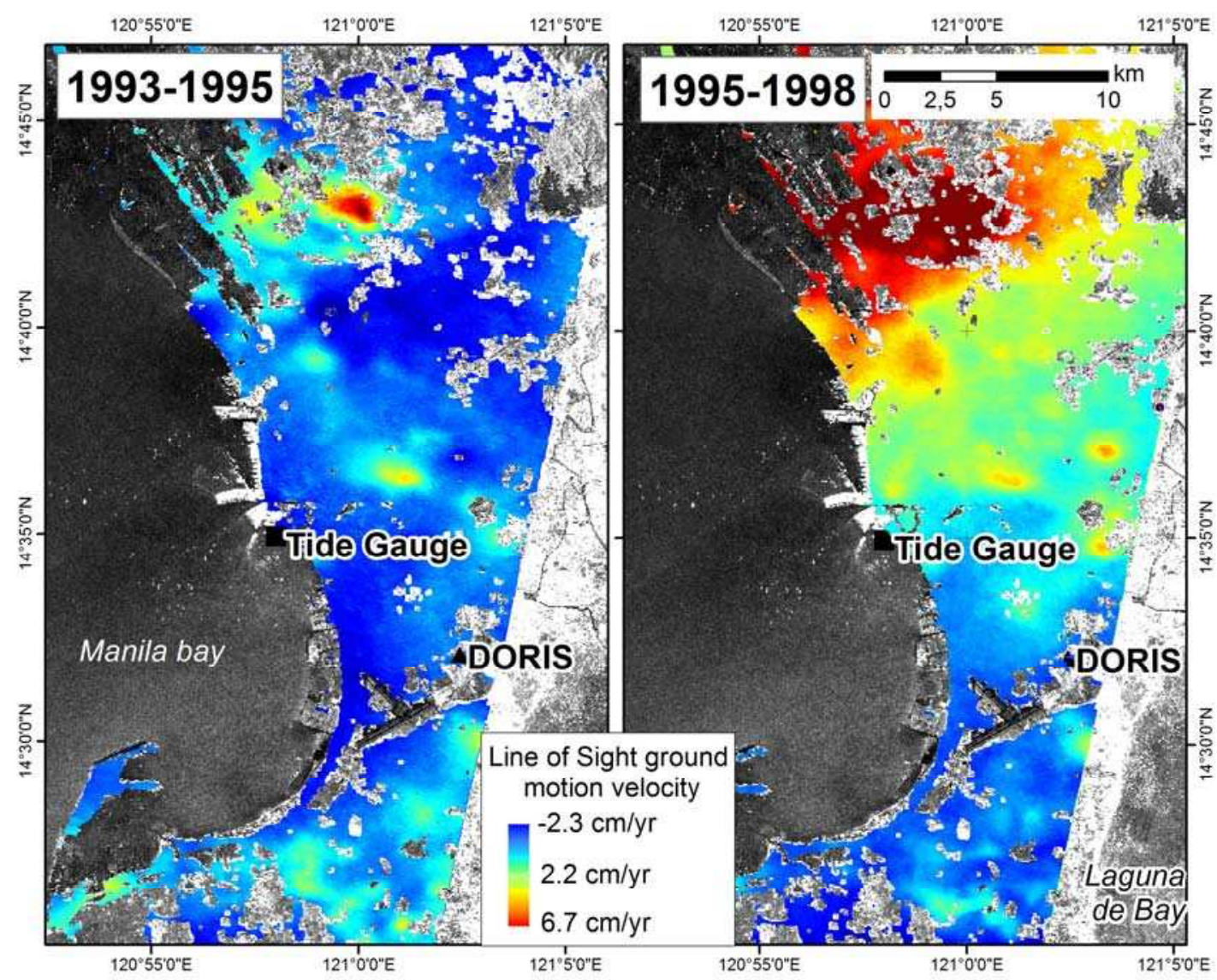

237 Figure 3b: Line of Sight ground motion velocity maps for 1993-1995 and 1995-1998. An increase in 238 subsidence rate in the northern part of the city appears between 1995 and 1998. 


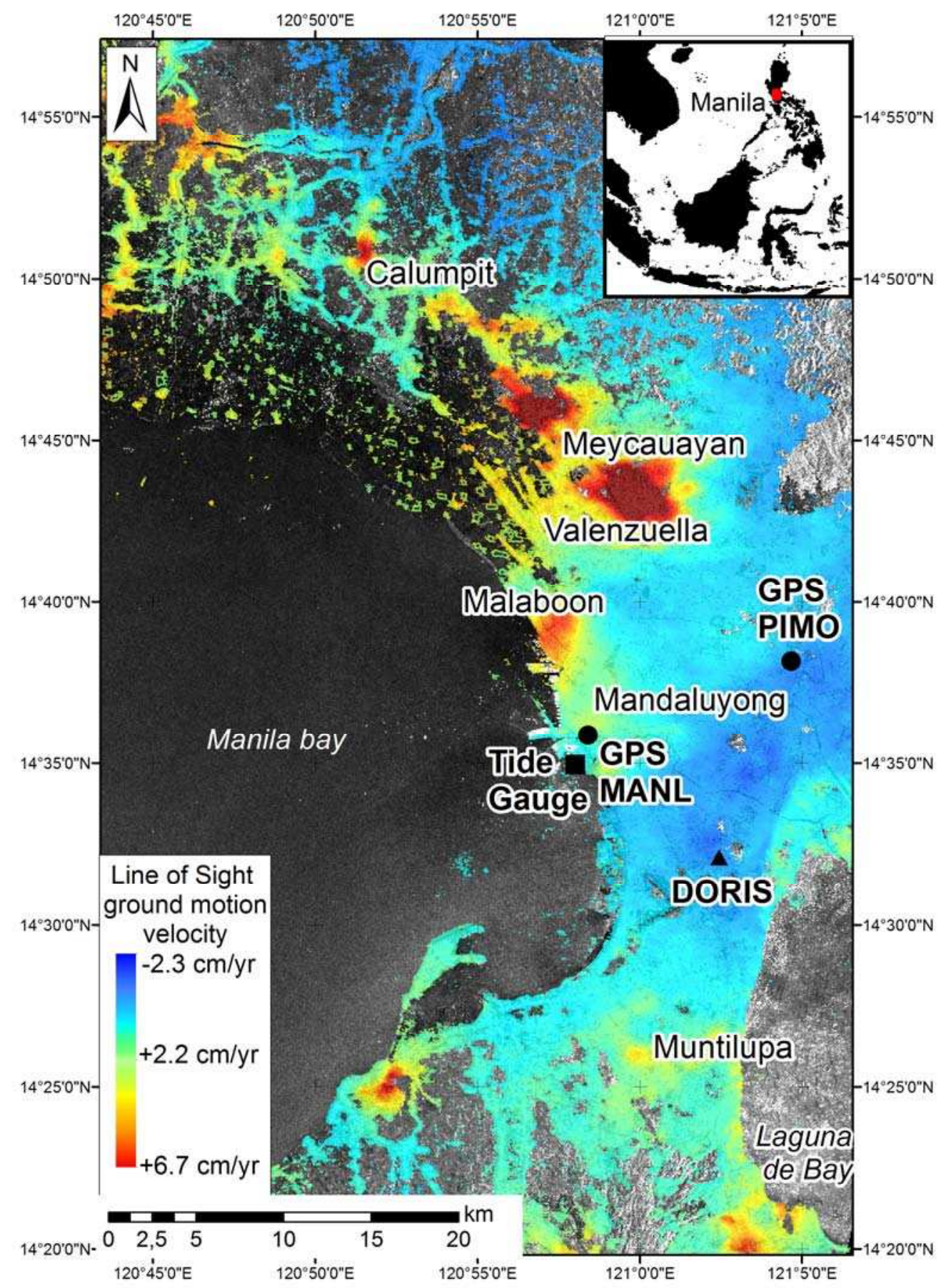

241 Figure 4a: Line of Sight ground motion velocity in cm/yr for the whole 2003-2010 period (EnviSat/ASAR 242 data). 


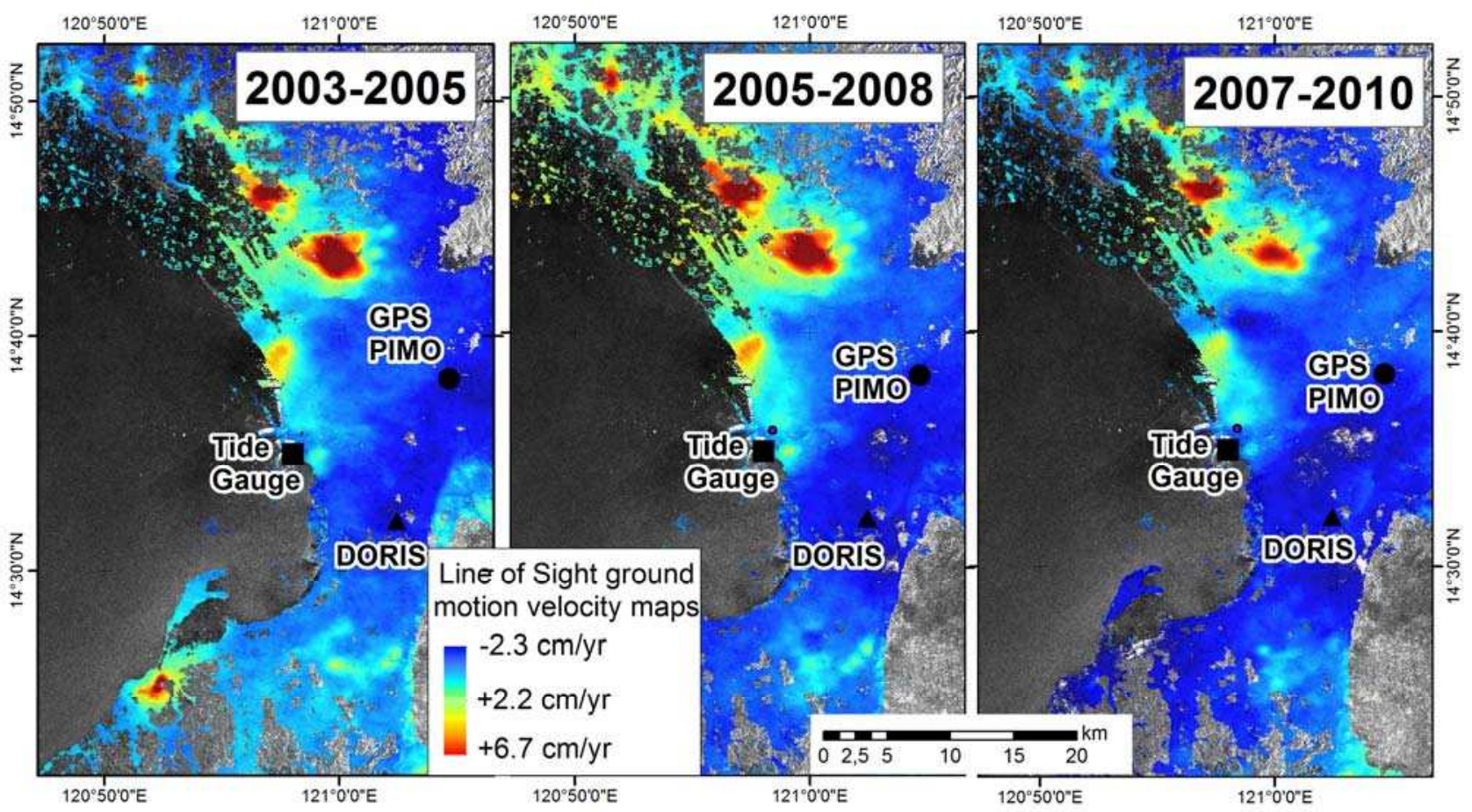

245 Figure 4b: Line of Sight ground motion velocity maps in cm/yr for 2003-2005, 2005-2008, and 2007-2010

\section{6 (EnviSat/ASAR data).}

248 The velocity maps reveal non-linear deformation rates. For example, Fig $3 b$ indicates that the subsidence

249 from 1995 to 1998 was quicker in the north-western part of Metro-Manila than from 1993 to 1995. How

250 reliable is this result? Due to the limited number of SAR images available from the ERS satellite, these

251 velocities maps might be partly affected by atmospheric noise or by slights errors in orbit calculation and

252 very large atmospheric effects at the scale of the imaged area might have resulted in tilts. In our approach,

253 these tilts are corrected by removing tilts on each signle interferogram (estimated using Fast Fourier

254 Transforms) and then the possible residual tilts are minimized over the whole data set during the stacking

255 procedure. While such errors are more difficult to correct when fewer SAR images are available, an

256 analysis of individual interferograms confirms that the acceleration of subsidence is affecting the same area

257 for several individual interferograms. This temporal correlation of interferograms as well as their velocity

258 indicates that these non-linear velocities cannot only result from atmospheric noise, and confirm the

259 acceleration of subsidence from 1995 to 1998 compared to 1993 to 1995 . Nevertheless, for the ERS data

260 set, we can consider the 1993-1998 map as more reliable than the two sub-sets (1993-1995 and 1995-

261 1998), because more interferograms were stacked and because the DORIS velocity estimation better

262 represents the average motion over the whole period. More SAR images are available from EnviSAT, thus 
making the results in figure $4 \mathrm{a}$ and $4 \mathrm{~b}$ more reliable. Several non-linear patterns can be observed in these maps, such as the extension of a coastal subsidence southward in the direction of the tide gauge, or the disappearance of a subsidence pattern on the southern shore of Manila Bay. These results therefore also highlight the non-linearity of the urban subsidence process in Manila.

Velocity maps not only display non-linear patterns, but also high rates of deformations. For example, deformation rates up to $13 \mathrm{~cm} / \mathrm{yr}$ were observed in Valenzuela and Meycauayan and rates of approximately $9 \mathrm{~cm} / \mathrm{yr}$ northwest of Guiguinto (note that for visual reason, we saturated the color palette to $6.7 \mathrm{~cm} / \mathrm{yr}$ ). In these sectors, deformation was much slower and spatially reduced between 1993 and 1995. The highest deformation rates observed in Valenzuela and Meycauayan are visible on the 1995-1998 and 2003-2005 maps (a decrease of the phenomenon in this sector is visible on this last map with respect to the first one), whereas a maximum was obtained after 2005 near Guiguinto.

Changes in the location and rates of groundwater extraction are a plausible explanation for this migration of the deformation maxima. As reported by Clemente et al. (2001), groundwater pumping in Manila has been multiplied by a factor of five since the 1970s because of population growth. This has resulted in a lowering of the groundwater table by several tens of meters. The authors also suggest land subsidence as a possible consequence of pumping. Clemente et al. (2001) provide piezometric maps which show that the deformation maps generated in this study are consistent with the locations of very low water table levels in

281 the 1990s. For instance, they reported that groundwater was intensively extracted in Muntilupa and

282 Valenzuela, where high ground-motion velocities in the 90's were observed in this research. This suggests 283 that many ground deformations observed using DInSAR in this research are direct consequences of 284 groundwater pumping in the Manila metropolitan area.

3.2 Monitoring of Temporal Evolution of Ground Deformations through Principal

\section{Components Analysis}

Because the results showed strong temporal variability, a principal components analysis was carried out to 290 highlight areas subject to deformation-rate changes. The idea was to separate areas with constant 291 deformation rates from areas affected by nonlinear deformation components. Principal components 292 analysis (PCA) was therefore applied to the five deformation-rate maps corresponding to the different 
periods studied. It was assumed that the first principal component (PC) was related to the common linear deformation (the first component being highly correlated with all the initial deformation maps) and the

295 second and third components to nonlinear deformations which differ among the five maps (upper-order components were neglected because the fourth eigenvalue was approximately one-twentieth of the first one). The three first eigenvalues were $\lambda_{1}=43, \lambda_{2}=11$ and $\lambda_{3}=4.3$.
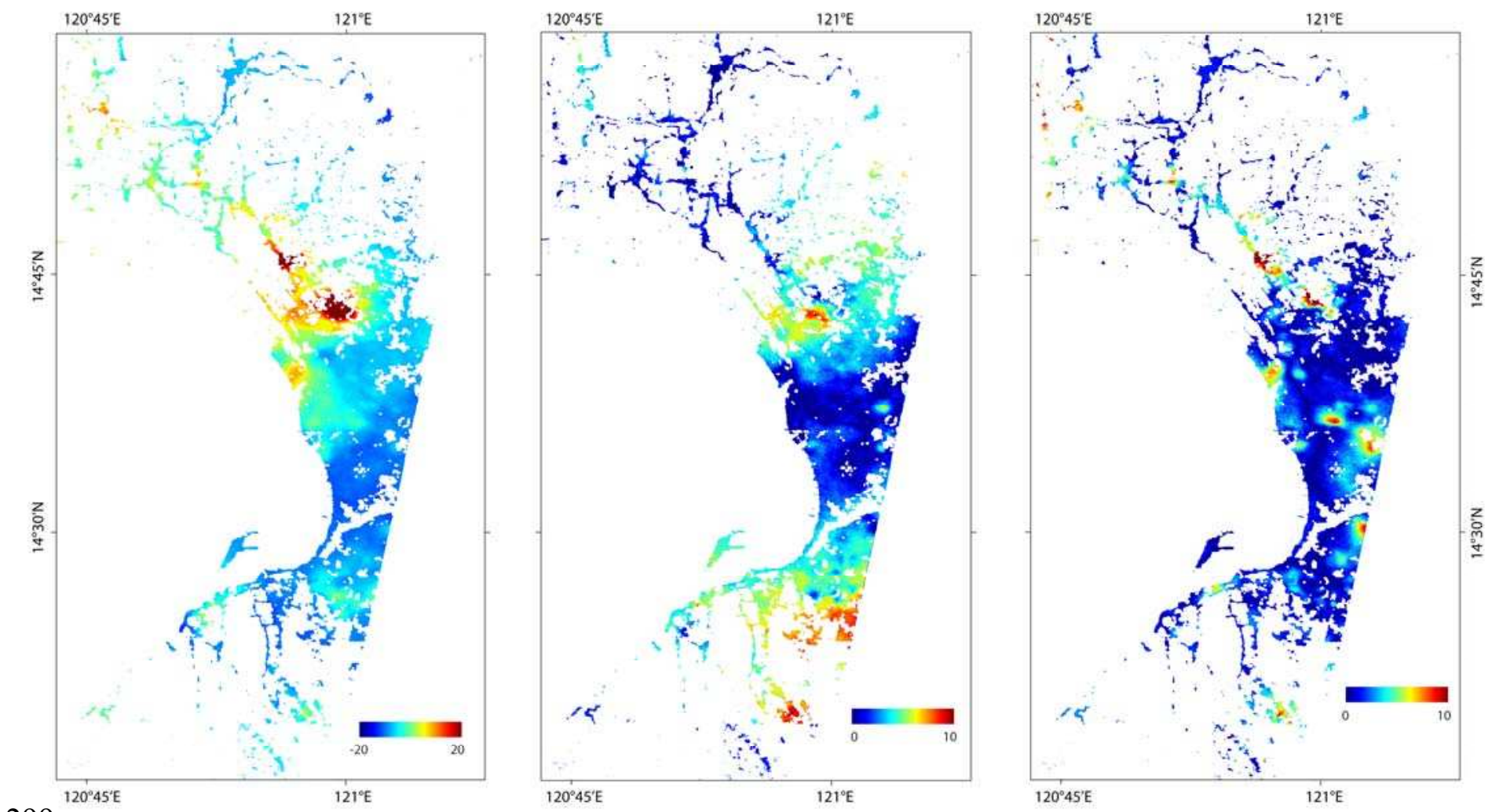

Figure 5: Maps showing the three first principal components. For the second and third components, the absolute values of the components are shown. Locations of the displacements are therefore identified by this information rather than their evolution (acceleration, deceleration).

305 Figure 5 highlights the observation that in addition to strong spatial variability, deformation patterns in

306 Manila show a complex temporal evolution. In particular, this figure indicates that in addition to the northern 307 part of the city (e.g., the area between Valenzuela and Meycauayan), the cities of Malaboon, Mandaluyong, 308 and Muntinlupa were affected by nonlinear deformations. Small areas spotted on the third component 309 deserve deeper investigation because temporal changes at short spatial wavelengths could have 
310 implications such as damage to buildings. Actual links with pumping locations in these areas should be 311 investigated, for example by identifying whether localized velocity changes can be correlated with the 312 installation of new pumping facilities during the study period.

\section{3.3 Deformation in the Marikina Valley Fault area}

316 To investigate displacement along the Marikina Valley Fault, an east-west directional filter was used to

317 highlight differential motion between each side of the fault (Fig. 6). Basically, the filtered image consists of 318 an along-column (approximately across-fault) deformation first derivative for which the histogram has been 319 adjusted and the result rescaled to obtain arbitrary values distributed between zero and one. This 320 procedure aims to provide better identification of linear features (similarly to a shaded map) that could be 321 associated with fault motion. Sections of the fault that possibly moved between 2007 and 2010 were then 322 located. Note that the ERS frames did not cover the fault, and therefore this observation is based only on 323 the ASAR data. The 2007-2010 maps clearly show differential displacement along the fault (Fig. 4b).

324 The observed fault section was divided into three sections based on their motion characteristics: A and C: 325 west side moves towards the sensor faster than east side; $B$ has the opposite behavior to $A$ and $C$. On the 326 three sections, the differential LOS displacement (identified on the deformation map) corresponds to approximately $5-15 \mathrm{~mm} / \mathrm{yr}$. Because the fault strike is oriented north-south, it can be assumed that pure

328 strike-slip motions have little influence on the deformation maps produced. Therefore, vertical motion must dominate the signal. Based on this assumption, the observed motion corresponds to up to $8 \mathrm{~mm} / \mathrm{yr}$ of

330 vertical displacement between the two sides of the fault. The source of this kind of motion is difficult to infer 331 based only on the DInSAR measures, which provide only one component of the deformation in three332 dimensional space. Deformation could be related either to tectonic strain (e.g., surface creep) or to 333 subsidence related to water extraction (as observed by Cigna et al., 2011). In this case, the fault would act 334 as a natural barrier. 


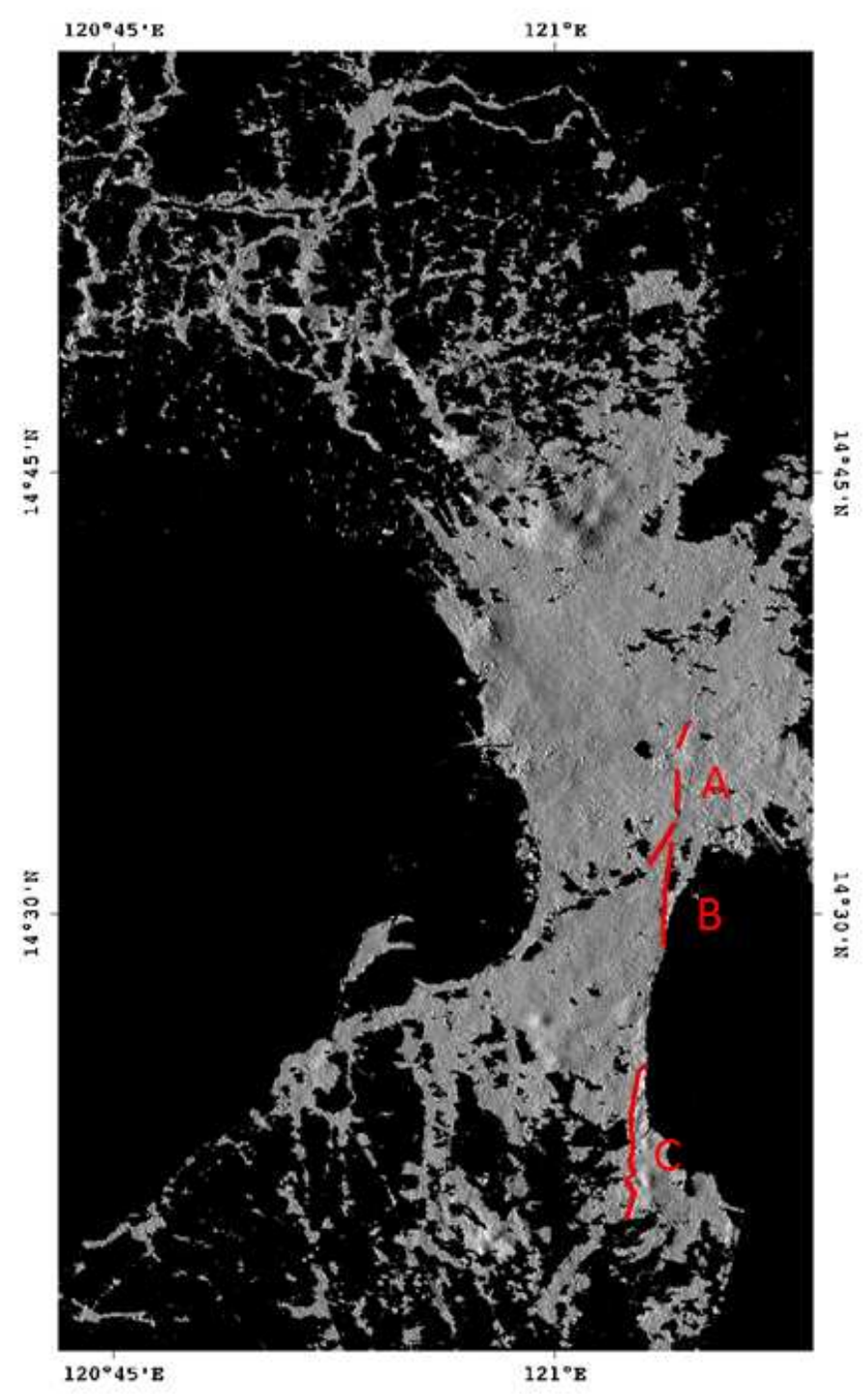

337 Figure 6: West-east directional filtering of the 2005-2010 deformation in arbitrary units. Bright areas

338 correspond to the highest values of W-E derivatives. The red line corresponds to possible sections of the

339 fault affected by differential displacement between the sides of the fault (located on linear features of the

340 filtered map). The three sections are identified using their different displacement behaviors.

342 A deeper analysis can be proposed. Based on both terrains offset measurements and magnitudes and 343 recurrences of earthquakes, Rimando \& Knuepfer (2006) have suggested that on the Rodriguez-Taguig 344 segment (corresponding to sections A and B in this paper), the slip rate should be approximately $7-10$ $345 \mathrm{~mm} / \mathrm{yr}$ and should be mostly horizontal. They observed that the ratio between vertical and horizontal 346 components of offsets is approximately 0.1 . Considering the orientation of the fault with respect to the 347 satellite-orbit path angle (between $0^{\circ}$ and $12^{\circ}$ ) and the SAR incidence angle (approximately $23^{\circ}$ ), $10 \mathrm{~mm} / \mathrm{yr}$ 
348 of horizontal motion would result in approximately $0.8 \mathrm{~mm} / \mathrm{yr}$ change in the LOS direction. This value is too

349 small to be measured by DInSAR. Therefore, non-tectonic subsidence seems more likely to be the cause 350 of the SAR signal for these sections. Section C of the fault (the Sucat-Binan segment) is characterized by 351 en-echelon elements. According to the authors, this segment is creeping, but they do not provide rate 352 estimations. This complicated behavior is not incompatible with vertical motion; the hypothesis that the 353 DInSAR observation shows creeping phenomena for this section cannot be rejected, but further dedicated 354 analysis would have to be performed to assess fault motion in this area.

357 Figures 7 and 8 show profiles and estimations of the relative displacements between each side of the fault 358 using a 200-pixel length and stacked on 100 pixels width based on the COSI-Corr tools (for details on 359 these tools and a discussion of their reliability and precision, refer to Ayoub et al., 2009). These figures 360 show that on sections $A$ and $B$, the recorded LOS displacements are variable with time (including an 361 inversion of the motion for section B). On the other hand, on section C, the LOS motion is fairly stable at 362 approximately $6 \mathrm{~mm} / \mathrm{yr}$ velocity (with a dispersion of approximately $2 \mathrm{~mm} / \mathrm{yr}$ ). These observations are 363 compatible with the fact that the fault mechanism is mainly N-S oriented strike-slip on A and B (blind to 364 DInSAR), and therefore the recorded vertical component of the motion must be due mainly to (variable) 365 non-tectonic causes. Section C, with its en-echelon structure, is known to creep (Rimando \& Knuepfer, 366 2006). Therefore, this research might have measured the vertical component of fault creep in this area. 


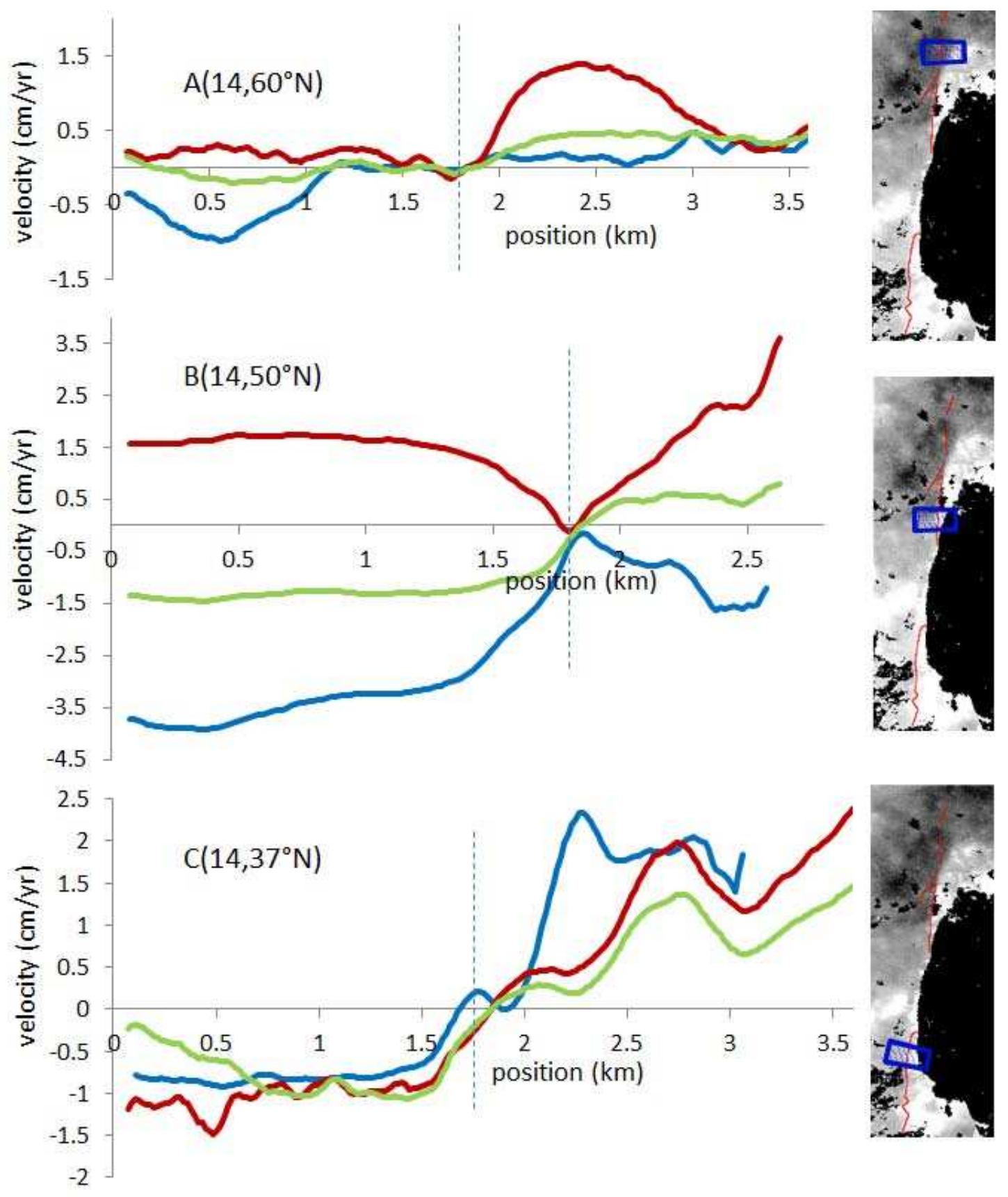

370 Figure 7: Relevant deformation across-fault profiles for each section: LOS velocities are given in $\mathrm{cm} / \mathrm{yr}$ and

371 the position in $\mathrm{km}$ (positive from west to east). These profiles are along fault stacks of 100 profiles 200

372 pixels in length (profile length: approximately $3.6 \mathrm{~km}$ ) according to the procedure implemented in the COSI-

373 Corr tool (Leprince et al., 2007; Ayoub et al., 2009). The fault is approximately located, based on the

374 directional filtering results, by the vertical dashed lines. In blue: profile derived from the 2003 2005 stack; in

375 red, 2007 2010; in green, 2003-2010 The insets show the location of the profile stacks with respect to the fault. 


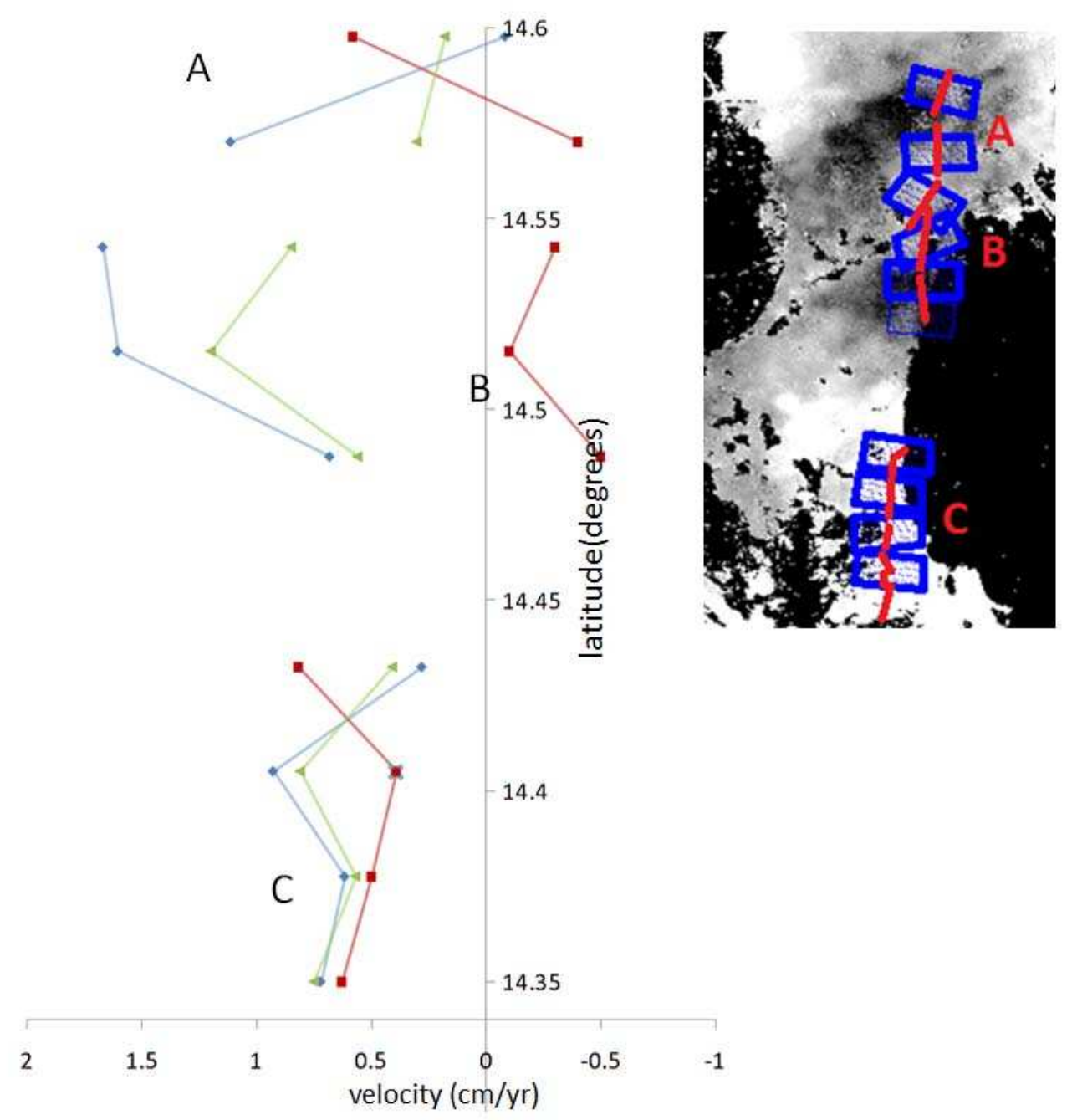

379 Figure 8: Differential LOS velocity for the sides of the fault (west side with respect to east side) versus 380 position on the fault (latitude). Velocities were obtained using the COSI-Corr tool. The 2003־2005 estimate 381 (in blue) is compared to that for $2007 \square 2010$ (in red) and 2003-2010 (green). Section C shows a 382 homogeneous behavior (vertical displacement of approximately $4 \llbracket 8 \mathrm{~mm} / \mathrm{yr}$ ), but the other sections show a 383 more temporally variable evolution (sign change) not compatible with creeping phenomena. The inset 384 shows the location of the profile stacks with respect to the fault.

4. Discussion 
391 While no leveling surveys are presently available in global data repositories (Santamaría-Gómez et al., 392 2012), a few geodetic instruments enable comparing our InSAR results with in-situ observations. These 393 geodetic instruments in Manila can be located on Fig. 2a. However, one permanent GPS station (GPS 394 MANL) provided a time series too short to be analyzed at the time of this study. As can be seen in Fig. 9 395 (blue), the DORIS instrument was nearly stable in average in the 1990s, but was affected by uplift in the 396 2000s (Fig. 9, green).

397 The GPS PIMO station was also subject to a slight uplift in the 2000s (Fig. 9, yellow). The differential 398 movement between PIMO and DORIS was consistently too small to be observed with DInSAR. During 399 2003-2010, the differential displacement between PIMO and the tide gauge (TG) as estimated from 400 DInSAR was approximately $10.7 \mathrm{~mm} / \mathrm{yr}+/-2.1 \mathrm{~mm} / \mathrm{yr}$, based on the sum of the variances of the DInSAR 401 deformation-rate measurements obtained on $200 \mathrm{~m}$ windows around the PIMO and TG locations. Once 402 corrected using the GPS absolute vertical motion, the resulting TG motion with respect to the reference 403 ellipsoid was approximately $8 \mathrm{~mm} / \mathrm{yr}$ of subsidence $(+/-2.2 \mathrm{~mm} / \mathrm{yr})$. To validate this result, the difference 404 between the sea-level variation recorded by AVISO data (Archiving, Validation and Interpretation of 405 Satellite Oceanographic data) and the TG data (Fig. 10) was calculated. The altimetric monthly sea-level 406 anomalies were obtained from the AVISO data server (http://www.aviso.oceanobs.com/en/altimetry.html).

407 These data are a multimission product (Jason 1-2, Envisat, Cryosat) with a spatial resolution of $4080.25^{\circ} \times 0.25^{\circ}$, starting in 1992 . They include all geophysical corrections, in particular the dynamic 409 atmospheric correction that accounts for the effects of atmospheric pressure and wind (Volkov et al., 2007). 410 To compare the tide-gauge data with the altimetry observations, this correction was added back in. The 411 most highly correlated grid point of the altimetry observations was chosen for comparison with in-situ 412 observations (the correlation was computed using de-seasoned and de-trended time series). Alternatives 413 such as the closest grid point or an average among nearby grid points around $1^{\circ}$ did not change the 414 results. The combination of the altimetric observations with the tide-gauge data highlights subsidence of up 415 to $10.1 \mathrm{~mm} / \mathrm{yr}+/-0.6 \mathrm{~mm} / \mathrm{yr}$.

417 Finally, in addition to the multi-annual ground motion variability observed by DInSAR, the GPS time series 418 also revealed seasonal vertical deformations with an amplitude of approximately $5.5 \mathrm{~mm}$. 


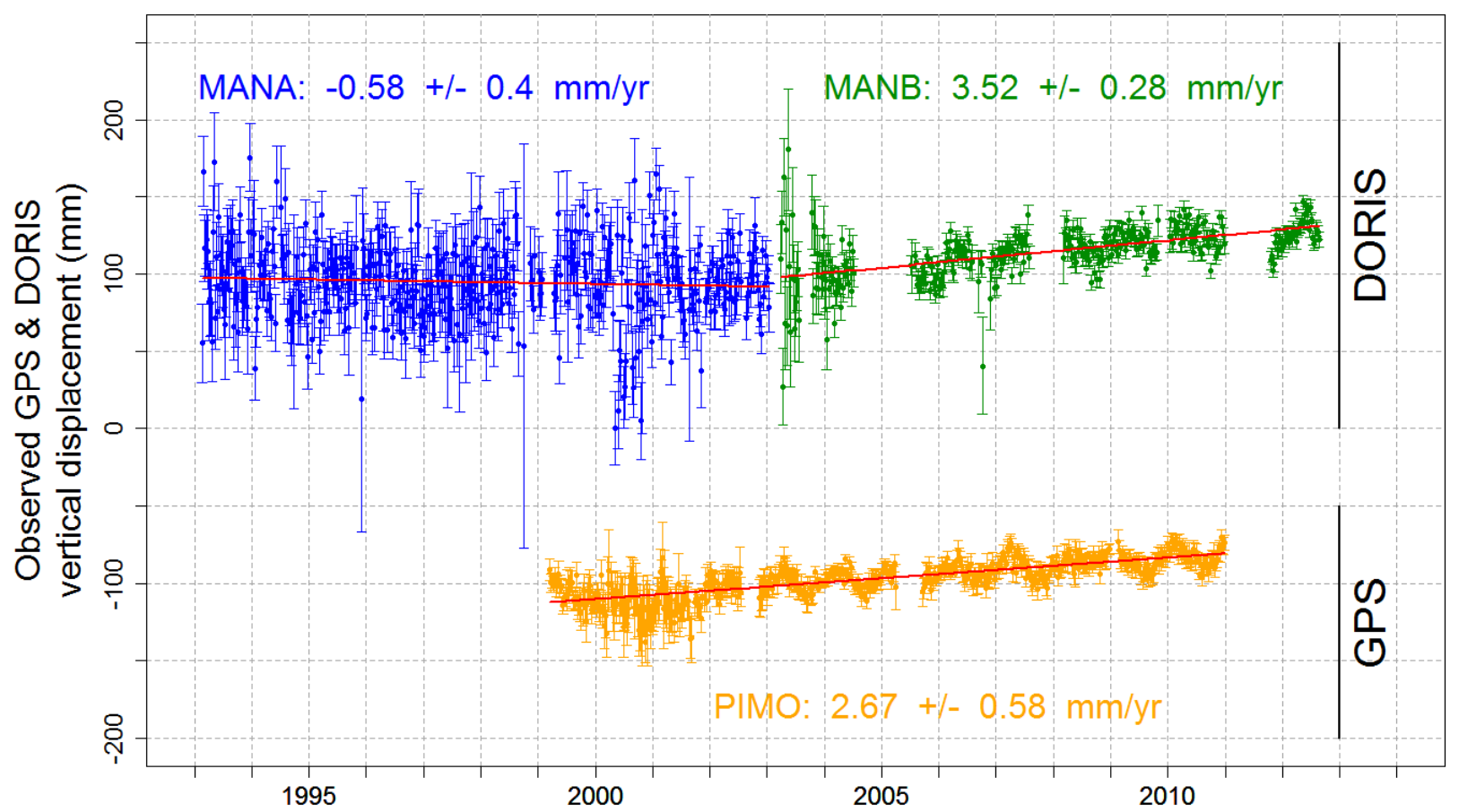

422 Figure 9: Observed DORIS (MANA/MANB) and GPS (PIMO) geocentric vertical displacements with respect 423 to the international reference frame. DORIS (blue before 2003, green after) and GPS (orange) position time 424 series are shown. Both stations were affected by uplift phenomena with similar rates. MANA and MANB 425 refer to successive DORIS instruments located at the same location (details on the instruments at http://ids426 doris.org/network/sitelogs.html /).

427

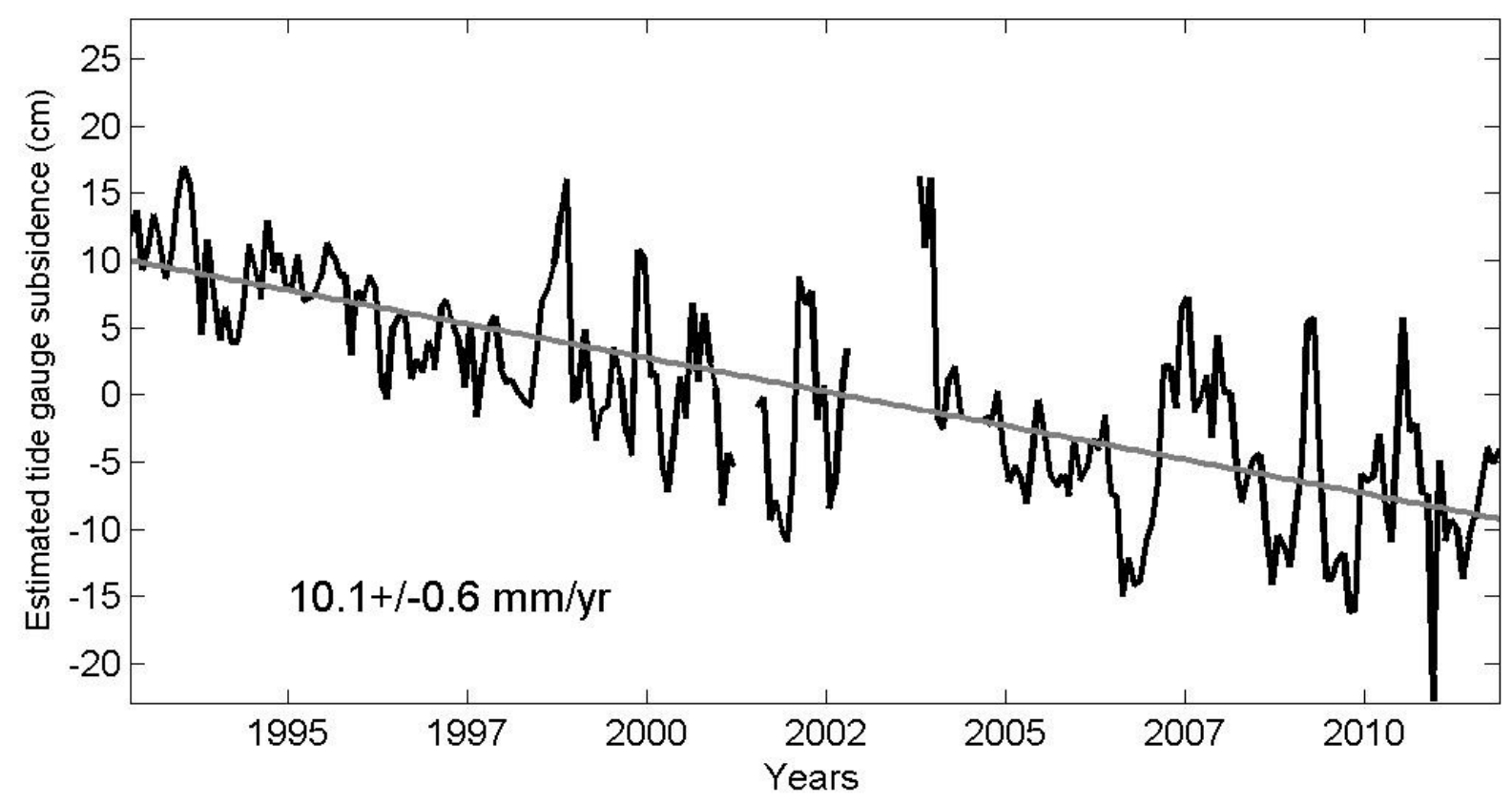




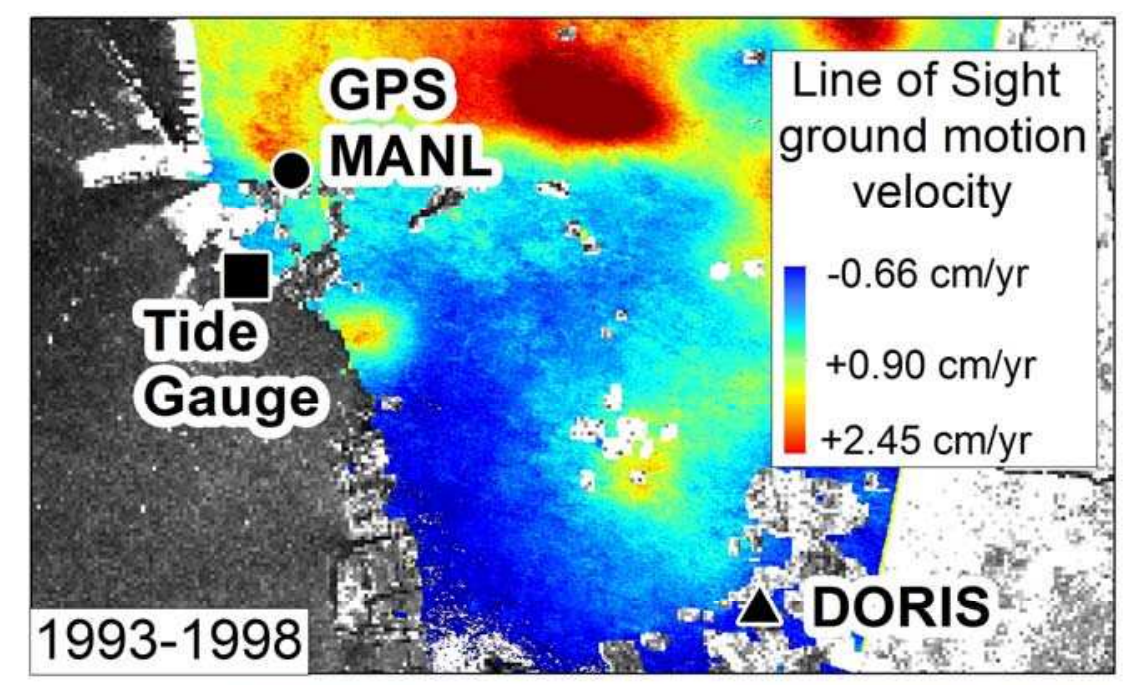

433 Figure 11: Close-up images showing Line of Sight ground motion velocity maps (cm/yr) close to the tide 434 gauge. The deformation reference was chosen according to the DORIS measurements. Although ground 435 motions affecting the location of geodetic instruments are much smaller than in other parts of Manila, they 436 are still sufficient to alter the measurements of the tide gauge significantly, thus calling into question its use 437 before 1993 for sea-level estimation studies.

4394.2 Implications for estimation of sea-level variation from TG measurements

440 Because sea-level rise exhibits significant regional variability (e.g., Meyssignac \& Cazenave, 2012), one 441 critical issue for better estimation of past sea level before the altimetry era (1993) is the analysis of long- 
442 term tide-gauge records. This question is particularly significant because there is a disagreement between 443 sea-level budgets as estimated (1) from tide gauges and (2) through independent evaluations of 444 thermosteric and continental ice-melting contributions (Munk, 2002).

445 Tide gauges measure sea level with respect to the land upon which they are grounded (local datum), while 446 global sea level refers to a geocentric reference frame. In other words, both the land and the sea can move 447 with respect to a geocentric reference frame. In practice, vertical ground motions can be removed from 448 tide-gauge measurements using a nearby GPS permanent station (e.g., Wöppelmann et al., 2007), 449 assuming that (1) the tide gauge and the GPS station follow the same vertical motion and (2) that the 450 deformation is linear. Under such conditions, extrapolation of the linear trend of $\sim 10$-years GPS time series 451 is valuable to estimate past land motion for at least 50 years. If the differential movements affecting the 452 instruments remained linear, advanced techniques such as PSI could be used as supplemental data to 453 reach the accuracy required of $(\sim 0.5 \mathrm{~mm} / \mathrm{yr})$ and subsequently to assess estimates of global sea-level rise 454 (approximately $1.7 \mathrm{~mm} / \mathrm{yr}$ between 1950 and 2010, Wöppelmann et al., 2013)

456 However, the results reported here show that none of the requirements necessary to estimate geocentric 457 sea-level rise from GPS-corrected tide-gauge data is fulfilled in the case study of Manila. Therefore, this 458 method cannot be used here because of highly variable ground motion. Moreover, the spatial and temporal 459 variability of the surface motion, affecting both the tide gauge and the reference GPS, prevents any 460 extrapolation from corrected gauge time series over the past 50 years. If the differential motion between the 461 GPS and the tide gauge can be estimated for the period monitored by the space-borne radar sensor, the 462 current motion is not representative of past motion (previous to the satellite era). In addition, if the area of 463 maximum subsidence, initially located in Malaboon city, migrates southward, the tide-gauge area could be 464 affected by increased subsidence in the future.

467 This study encourages DInSAR monitoring at locations where long-term tide-gauge time series are 468 corrected using a distant permanent GPS to verify whether the typical assumptions used to combine the 469 datasets and to estimate geocentric sea-level variation are applicable. 
473 Subsidence in coastal cities has many effects, potentially ranging from increased frequency of flooding to 474 damage to buildings. In the specific context of Manila, this study has provided the following responses to 475 the questions raised in the introduction:

(1) What was the spatial and temporal variability of ground-surface deformations in Manila from 1993 to 2010 ? This study has presented evidence for high rates of spatially and temporally variable ground deformation in the Manila urban area (Philippines) based on space-borne SAR interferometry during the last two decades. Displacements up to $15 \mathrm{~cm} / \mathrm{yr}$ with temporal and spatial variability have been observed. These ground motions are very likely related to groundwater pumping because the Manila urban area is known to be affected by subsidence due to intensive groundwater extraction (Clemente et al., 2001) and due to ground motion along the fault. Although the origin of this latter motion could be tectonic, it is suggested here that the observed ground motion along the fault is actually likely to be related to groundwater pumping as well (except on the Sucat-Binan segment).

(2) To which extent do these deformations affect the locations of the tide gauge, the GPS stations, and the DORIS stations? Observed ground motions affect the locations of several geodetic instruments and therefore alter the potential of using their time series to understand past sea levels.

(3) What are the possibilities for using sea-level time series before 1993 in Manila? The Manila tidegauge time series cannot be corrected from its own motion for long-term sea-level estimation on the basis of existing GPS data because the GPS station also experiences variable subsidence and cannot therefore provide an estimate of the deformation occurring during the entire duration of the

496 From a methodological point of view, this study provides an example of a site where InSAR is helpful in 497 assessing city-scale subsidence or uplift as well as the related consequences for measurements obtained 498 from geodetic instruments located in the city. Because of its deformation characteristics (location, extent, 499 and variable temporal evolution), the Manila metropolitan area has been revealed to be a challenging test 500 site both for application of deformation-monitoring techniques and for surface deformation-related risk 501 management. The approach proposed in this study could enable assessment of the usability of a number 
of tide gauges suspected of having been affected by local ground motions and finally could provide help in estimating sea-level evolution over the past century.

504

505

506

\section{ACKNOWLEDGEMENTS}

The work presented in this article was supported by the French National Research Agency (ANR) through the CEP-2009 program ("Coastal environmental changes: impact of sea level rise" (CECILE) project under grant number ANR-09-CEP-001-01). The SONEL data assembly center supported by INSU/CNRS is also acknowledged for providing comprehensive access to GPS data and metadata. We also thank the European Space Agency for providing data and four anonymous reviewers for their constructive comments.

\section{REFERENCES}

514 Ayoub, F., Leprince S., \& Keene, L. (2009). Users Guide to COSI-CORR Co-registration of Optically

515 Sensed Images and Correlation, Pasadena: California Institute of Technology

516 (http://www.tectonics.caltech.edu/slip history/spot coseis/pdf files/cosi-corr guide.pdf)

517 Bock, Y., Wdowinski, S., Ferretti, A., Novali, F., \& Fumagalli, A. (2012). Recent subsidence of the Venice

518 Lagoon from continuous GPS and interferometric synthetic aperture radar. Geochemistry Geophysics

519 Geosystems, in press, doi:10.1029/2011GC003976.

520 Brooks, B.A., Merrifield, M.A., Foster, J., Werner, C.L., Gomez, F., Bevis, M., \& Gill, S. (2007). Space

521 geodetic determination of spatial variability in relative sea level change, Los Angeles basin. Geophysical 522 Research Letters, 34, L01611.

523 Clemente, R., Tabios, G., Abracosa, R., David, C., \& Inocencio, A. (2001). Groundwater supply in Metro

524 Manila: distribution, environmental and economic assessment. Discussion Paper Series, 2001-2006,

525 Makati: Philippine Institute for Development Studies.

526 Chaussard, E., Amelung, F., Abidin, H., \& Hong, S.H. (2013). Sinking cities in Indonesia: ALOS PALSAR

527 detects rapid subsidence due to groundwater and gas extraction. Remote Sensing of the Environment 128, $528 \quad 150-161$. 
529 Cigna, F., Osmanoğlu, C., Cabral-Cano, E., Dixon, T., Ávila-Olivera, J., Garduño-Monroy, V., DeMets, C., 530 \& Wdowinski, S. (2012). Monitoring land subsidence and its induced geological hazard with Synthetic 531 Aperture Radar Interferometry: a case study in Morelia, Mexico, Remote Sensing of Environment, 117, $532 \quad 146-161$

533 Daag, A., Bacolcol, T., Monstes, A., Kawai, M., \& Tsutsui, K. (2011). Use of differential interferometry to 534 monitor ground deformation of Mayon Volcano and land subsidence north of Metro Manila and Bulacan. 535 Proceedings, 24th Annual Geological Convention of the Geological Society of the Philippines, Quezon City, 536 December 8-9, 2011.

537 Ferretti, A., Prati, C., \& Rocca, F. (2001). Permanent scatterers in SAR interferometry. IEEE Transactions on Geoscience and Remote Sensing 39(1), 8-20.

539 Hanson, S., Nicholls, R., Ranger, N., Hallegatte, S., Corfee-Morlot, J., Herweijer, C., \& Chateau, J. (2011).

540 A global ranking of port cities with high exposure to climate extremes. Climatic Change 104, 89-111.

541 Hanssen, R. (ed.) (2001). Radar Interferometry: Data Interpretation and Error Analysis, Dordrecht: Kluwer 542 Academic.

543 IOC (2012). The Global Sea Level Observing System Implementation Plan 2012. Intergovernmental

544 Oceanographic Commission, Technical Series No. 100.

545 Jacinto, G., Azanza, R., Velasquez, I., \& Siringan, F. (2006). Manila Bay: environmental challenges and 546 opportunities. In: Environment in Asia Pacific Harbors, 309-328, Dordrecht: Springer.

547 Kim, S., Wdowinski, S., Dixon, T., Amelung, F., Kim, J., \& Won, J. (2010). Measurements and predictions 548 of subsidence induced by soil consolidation using persistent scatterer InSAR and a hyperbolic model. 549 Geophysical Research Letters 37, L05304.

551 Lagios, E., Parcharidis, I., Sakkas, V., Raucoules, D., Feurer, D., Le Mouelic, S., King, C., Carnec, C., 552 Novali, F., Ferretti, A., Capes, R., \& Cooksley, G., (2006). Subsidence monitoring within the Athens basin 553 using advanced space radar interferometric techniques. Earth, Planets, and Space 58, 505-513. 
554 Le Mouelic, S., Raucoules, D., Carnec, C., \& King, C. (2005). A least-squares adjustment of multi-temporal 555 InSAR data: application to the ground deformation of Paris. Photogrammetric Engineering and Remote 556 Sensing 71, 197-204.

557 Leprince, S., Ayoub, F., Klinger, Y., \& Avouac, J. (2007). Co-registration of optically sensed images and 558 correlation (COSI-Corr): an operational methodology for ground-deformation measurements. Proceedings, 559 IEEE International Geoscience and Remote Sensing Symposium (IGARSS 2007), Barcelona, July 2007.

560 Massonnet, D. , \& Feigl, K. (1998). Radar interferometry and its application to changes in the Earth's 561 surface. Reviews of Geophysics 36(4), 441-500.

562 Meyssignac, B., \& Cazenave, A. ( 2012). Sea level: A review of present-day and recent past changes and 563 variability. Journal of Geodynamics 58, 96-109.

564 Munk, W. (2002). Twentieth-century sea level: an enigma. Proceedings of the National Academy of 565 Sciences of the United States of America 99, 6550-6555.

566 National Statistics Office of the Republic of the Philippines (2010). 2010 Census of Population and 567 Housing, National Capital Region. Available at :

568 http://www.census.gov.ph/sites/default/files/attachments/hsd/pressrelease/National Capital Region.pdf.

569 Pepe, A., Sansosti, E., Berardino, P., \& Lanari, R. (2005). On the generation of ERS/ENVISAT DInSAR 570 time series via the SBAS technique. IEEE Geoscience and Remote Sensing Letters 2(3), 265-269.

571 Peltzer G., Crampé F., Henley, S., \& Rosen P.(2001). Transient strain accumulation and fault interaction in 572 the Eastern California shear zone, Geology, 29: 975-978

573 Raucoules, D., Bourgine, B., De Michele, M., Le Cozannet, G., Closset, L., Bremmer, C., Veldkamp, H., 574 Tragheim, D., Bateson, L., Crosetto, M., Agudo, M., \& Engdahl, M. (2009). Validation and intercomparison 575 of Persistent Scatterers Interferometry: PSIC4 project results. Journal of Applied Geophysics 68, 335-347.

576 Raucoules, D., Parcharidis, I., Feurer, D., Novalli, F., Ferretti, A., Carnec, C., Lagios, E., Sakkas, V., Le 577 Mouelic, S., Cooksley, G., \& Hosford, S. (2008). Ground deformation detection of the greater area of 
580 Rimando, R., \& Knuepfer, P. (2006). Neotectonics of the Marikina Valley Fault system (MVFS) and tectonic 581 framework of the structures in northern and central Luzon, Philippines. Tectonophysics 415, 17-38.

582 Rodolfo, K.S., \& Siringan, F.P. (2006). Global sea-level rise is recognized, but flooding from anthropogenic 583 land subsidence is ignored around northern Manila Bay, Philippines. Disasters 30, 118-139.

584 Santamaría-Gómez, A., Gravelle, M., Collilieux, X., Guichard, M., Miguez, B.M., Tiphaneau, P., \& 585 Wöppelmann, G. (2012). Mitigating the effects of vertical land motion in tide gauge records using a state-of586 the-art GPS velocity field. Global and Planetary Change 98-99, 6-17.

587 Siringan, F.P., \& Ringor, C.L. (1998). Changes in bathymetry and their implications for sediment, dispersal 588 and rates of sedimentation in Manila Bay. Science Diliman 10(2), 12-26.

590 Tandanand, S., \& Powell, R. (1991). Determining horizontal displacement and strain due to subsidence.

591 Washington D.C.: U.S. Dept. of the Interior, Bureau of Mines.

592

593 Usai, S. (2003). A least-squares database approach for SAR interferometric data. IEEE Transactions on 594 Geoscience and Remote Sensing 41(4), 753-760.

595

596 Volkov, D.L., Larnicol, G., \& Dorandeu, J. (2007). Improving the quality of satellite altimetry data over 597 continental shelves. Journal of Geophysical Research 112, C06020.

598 Williams, S.D.P. (2008). CATS: GPS coordinate time series analysis software. GPS Solutions 12(2), 147599153.

600 Willis, P., Fagard, H., Ferrage, P., Lemoine, F.G., Noll, C.E., Noomen, R., Otten, M., Ries, J.C., Rothacher, 601 M., Soudarin, L., Tavernier, G., \& Valette, J.J. (2010). The International DORIS Service: toward maturity. 602 In: DORIS: Scientific Applications in Geodesy and Geodynamics, Advances in Space Research 603 45(12):1408-1420. 
604 World Bank (2010). Climate risk and adaptation in Asian Coastal Megacities: a synthesis report. 97p.,

605 available at : http://siteresources.worldbank.org/EASTASIAPACIFICEXT/Resources/226300-

606 1287600424406/coastal megacities fullreport.pdf.

607 Wöppelmann, G., Miguez, B.M., Bouin, M.N., \& Altamimi, Z. (2007). Geocentric sea-level trend estimates

608 from GPS analyses at relevant tide gauges world-wide. Global and Planetary Change 57, 396-406.

609 Wöppelmann, G., Le Cozannet, G., de Michele, M., Raucoules, D., Cazenave, A., Garcin, M., Hanson, S.,

610 Marcos, M., \& Santamaría-Gómez A. (2013). Is subsidence increasing the exposure to sea level rise

611 impacts in Alexandria, Egypt? Geophysical Research Letters 40, 1-5.

612 Wegmuller, U., Werner, C., \& Strozzi, T., (1998). SAR interferometric and differential interferometric 613 processing chain. Proceedings, International Geoscience and Remote Sensing Symposium (IGARSS), 2 , 614 1106-1108, July 1998, Seattle.

615

616 Wright, T., Parsons, B., \& Lu, Z. (2004). Towards mapping surface deformation in three dimensions using 617 InSAR. Geophysical Research Letters 31(1), L01607.

618

619 Zebker, H., Rosen, P., \& Hensley, S. (1997). Atmospheric effects in interferometric synthetic aperture radar 620 surface deformation and topographic maps, Journal of Geophysical Research: Solid Earth - B2 102, 21566212202 